\title{
Contribution of peripheral chemoreceptors to ventilation and the effects of their suppression on exercise tolerance in chronic heart failure
}

\author{
T P Chua, P P Ponikowski, D Harrington, J Chambers, A J S Coats
}

\begin{abstract}
Objectives-To assess the contribution of peripheral chemoreceptors to ventilation and the effects of continuous inspired oxygen on exercise tolerance in chronic heart failure patients. The role of peripheral chemoreceptors in mediating hyperpnoea in chronic heart failure is unknown. Hyperoxia is known to suppress the peripheral chemoreceptor drive. The magnitude of decrease in ventilation with transient inhalations of oxygen thus provides a measure of the contribution of the peripheral chemoreceptors to ventilation. Setting-Tertiary specialist hospital.

Subjects and methods-Three breaths of $100 \%$ oxygen were given at rest and also during cycle ergometry at $25 \mathrm{~W}$ to 8 healthy controls (age $52.0(4 \cdot 7)$ (SEM) years) and 13 patients with chronic heart failure (age $60.5(2 \cdot 1)$ years $(P=N S)$; radionuclide left ventricular ejection fraction $25 \cdot 5(4 \cdot 3) \%)$. The peripheral chemoreceptor sensitivity was also measured by assessing the ventilatory response to hypoxia using transient inhalations of pure nitrogen. Another group of 12 patients with chronic heart failure (age $65.5(1 \cdot 5)$ years; left ventricular ejection fraction $21 \cdot 3(3 \cdot 0) \%$ ) underwent treadmill exercise testing on 2 occasions, breathing air or $100 \%$ oxygen in a randomised single-blind manner, to examine the effects of continuous inspired oxygen on exercise tolerance.
\end{abstract}

Results-The reduction in ventilation with transient hyperoxia was $18 \cdot 1(2.9) \%$ $v 17.9(2.6) \%(P=N S)$ at rest and 20.4 $(2.8) \% v 21.0(1.6) \%(P=N S)$ during cycle ergometry, for controls and patients respectively. The hypoxic chemosensitivity was higher in patients $(0.232(0.022)$ v $\left.0.572(0.082) 1 / \mathrm{min} / \% \mathrm{SaO}_{2} ; P=0.002\right)$. Continuous inspired oxygen increased exercise time (517 (31) $v 455$ (27) seconds; $P=0 \cdot 003$ ), and a trend towards a reduction in the ventilatory response to exercise, characterised by the regression slope relating ventilation to carbon dioxide output, was evident $(31 \cdot 27(2 \cdot 60)$ v $34 \cdot 19$ (2.35); $P=0.08)$.

Conclusions-Despite an increased peripheral chemoreceptor sensitivity, the proportionate contribution of peripheral chemoreceptors to ventilation remained similar in heart failure patients (about $20 \%$ ). This suggests that the peripheral chemoreceptors are not the main media- tor of increased ventilation and there are other non-peripheral chemoreceptormediated mechanisms involved. Hyperoxia reduced ventilation at rest and during cycle ergometry. The increase in exercise duration with continuous inspired oxygen that was associated with a reduction in exercise ventilatory response suggests that suppression of the peripheral chemoreceptors may improve exercise tolerance; the effects of possible reduced skeletal muscle anaerobiosis cannot be excluded, however.

(Heart 1996;76:483-489)

Keywords: chronic heart failure; chemoreceptors; ventilation; exercise tolerance

Patients with chronic heart failure show reduced exercise tolerance which may be related to dyspnoea and fatigue. They also demonstrate increased ventilation when compared with healthy subjects. ${ }^{12}$ This increased ventilation may partially contribute to the symptom of dyspnoea. ${ }^{3}$ The mechanisms underlying the increased ventilation especially during exercise are not fully understood. We have shown that both hypoxic and hypercapnic chemosensitivity are enhanced in patients with chronic heart failure and may partly contribute to the increased ventilation. ${ }^{4}$ Hypoxic chemosensitivity is mediated by peripheral chemoreceptors. Hyperoxia is known to suppress the peripheral chemoreceptors and the consequent fall in ventilation therefore reflects their contribution to ventilation. ${ }^{5}$

Although we found an increase in chemosensitivity, the contribution of peripheral chemoreceptors to ventilation in patients with chronic heart failure remains unknown. It may be that the contribution of peripheral chemoreceptors to overall control of ventilation remains unchanged because such control is likely to be multifactorial, possibly involving central neurogenic drive, ${ }^{6}$ central chemoreceptors ${ }^{4}$ cardiac mechanoreceptors, ${ }^{7-9}$ and muscle ergoreceptors, ${ }^{10}$ and the input of some, if not all, of these factors may also be increased. On the other hand, if the contribution of the peripheral chemoreceptors is enhanced, it suggests that its role in the control of ventilation may be more than that of the other factors in chronic heart failure. It has been shown by Dejours and other investigators that the contribution of the peripheral chemoreceptors to ventilation in normal subjects is between $10 \%$ 
Table 1 Characteristics of healthy controls and patients with chronic heart failure who participated in the first part of this study looking at the effects of transient hyperoxia on ventilation

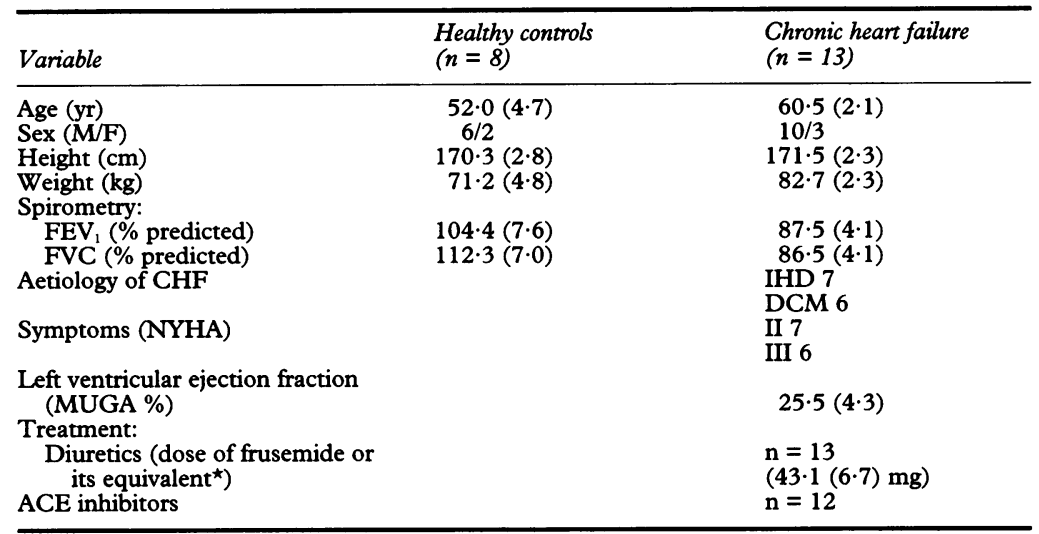

Values expressed as means (SEM).

$\mathrm{FEV}_{1}$, forced expiratory volume in 1 second; FVC, forced vital capacity; NYHA, New York $\mathrm{FEV}_{1}$, forced expiratory volume in 1 second; FVC, forced vital capacity; NYHA, New York graphy; IHD, ischaemic heart disease; DCM, idiopathic dilated cardiomyopathy; ACE inhibitors, angiotensin-converting enzyme inhibitors.

${ }^{\star} 1 \mathrm{mg}$ bumetanide is regarded as equivalent to $40 \mathrm{mg}$ frusemide.

and $20 \% . .^{511} 12$ In this study, we investigated the contribution of the peripheral receptors to ventilation at rest and during mild exercise by transient hyperoxic suppression. Transient hyperoxia was used in order to prevent other opposing confounding factors such as the accumulation of carbon dioxide consequent to the fall in ventilation. ${ }^{5}$ In the second part of this study, however, we examined the effects of continuous inspired oxygen on incremental treadmill exercise.

\section{Patients and methods}

PART 1

Thirteen patients with chronic heart failure (10 men; age $60.5(2 \cdot 1)$ years; radionuclide left ventricular ejection fraction $25 \cdot 5(4 \cdot 3) \%$, range $8-43 \%$ ) and eight healthy control subjects (six men; age $52.0(4.7)$ years) participated in the first part of this study. All patients had had stable heart failure for at least six months and none had a history of acute decompensation within this period. All subjects were well acquainted with the exercise laboratory and had previously participated in cardiopulmonary exercise testing. The characteristics of the study groups are given in table 1 .

Subjects were told to avoid products containing caffeine on the morning of the test. They were seated, wore a noseclip, and after a period of quiet breathing through a pneumatic respiratory valve (Innovision, Odense, Denmark), they were given transient inhalations of $100 \%$ oxygen for three breaths (without their being aware of the timing of these inhalations) from a 4 litre reservoir bag quietly refilled with pure oxygen. Minute ventilation was measured breath-by-breath using a heated pneumotachograph and oxygen and carbon dioxide were continuously monitored at the mouth by mass spectrometry (Amis 2000, Innovision, Odense, Denmark). The pneumotachometer and mass spectrometer were calibrated before each test. The average minute ventilation of the preceding five breaths before the inhalation of $100 \%$ oxygen was taken as the baseline ventilation. The minute ventilation of the 10 breaths after the start of oxygen inhalation was analysed and that of the smallest breath noted. This was repeated, on average, four times for each subject after the end tidal oxygen had returned to its initial level. The mean baseline ventilation and that of the smallest breath after hyperoxia were calculated from these four transients. The magnitude of the fall in ventilation, both in absolute values as well as expressed as a percentage of the baseline ventilation, was accordingly analysed.

After a 20 minute interval, the subjects then had the same procedure repeated as above but this time during mild exercise on a cycle ergometer (Tunturi, Finland) at $25 \mathrm{~W}$ for about 12 minutes. Inhalations of $100 \%$ oxygen were not given until three minutes after the onset of exercise to allow a steady state to develop. ${ }^{13}$

On another day, the subjects returned for the assessment of their peripheral chemosensitivity. This was performed using the transient hypoxic ventilatory response test which we have described in full elsewhere. ${ }^{14}$ This method was chosen for practical and safety reasons since subjects were not subjected to prolonged episodes of hypoxia. In brief, after a period of quiet breathing, subjects were given transient inhalations of pure nitrogen, without being aware of the timing of these inhalations, for two to eight breaths. This was repeated 10 times so as to provide a wide range of arterial oxygen saturations from $75 \%$ to $100 \%$, with appropriate intervals of air breathing between exposures to allow arterial oxygen saturation and end tidal carbon dioxide to return to baseline. The maximal ventilation following each period of nitrogen inhalation was obtained by averaging the largest two consecutive breaths using breath-by-breath analysis with a heated pneumotachograph (Amis 2000, Innovision, Odense, Denmark), calibrated before each test. Arterial oxygen saturation was measured using a pulse oximeter (Model N-200E, Nellcor, Hayward, California, USA) set at fast mode with a response time of 2-3 seconds and a lightweight probe clipped gently on the patients' right ear lobe. Minute ventilation was plotted against the lowest arterial oxygen saturation reached for each period of nitrogen inhalation. The hypoxic chemosensitivity was obtained as the slope of the regression line relating minute ventilation to arterial oxygen saturation and expressed in terms of litres per minute per percent oxygen saturation $\left(1 / \mathrm{min} / \% \mathrm{SaO}_{2}\right)$.

PART 2

We assessed the effects of continuous inspired $100 \%$ oxygen on exercise ventilation and exercise tolerance in a second group of 12 patients with chronic heart failure (all men; age 65.5 $(1.5)$ years; radionuclide left ventricular ejection fraction $21 \cdot 3(3 \cdot 0) \%$, range $12-39 \%$ ). They were stable and did not have a history of acute decompensation for at least six months before the study. Patient characteristics are given in table 2 . 
Table 2 Clinical characteristics of patients with chronic heart failure who participated in the second part of the study which examined the effects of continuous inspired oxygen during exercise

\begin{tabular}{ll}
\hline Characteristic & Value \\
\hline Age (yr) & $65 \cdot 5(1 \cdot 5)$ \\
Sex & All male \\
Height $(\mathrm{cm})$ & $172 \cdot 9(1 \cdot 8)$ \\
Weight $(\mathrm{kg})$ & $77 \cdot 4(3 \cdot 1)$ \\
Spirometry: & $90 \cdot 5(4 \cdot 9)$ \\
$\quad$ FEV $(\%$ predicted) & $89 \cdot 9(4 \cdot 4)$ \\
FVC (\% predicted) & IHD 8 \\
Aetiology of CHF & DCM 4 \\
Symptoms (NYHA) & II 6 \\
MUGA left ventricular ejection & III 6 \\
$\quad$ fraction (\%) & $21 \cdot 3(3 \cdot 0)$ \\
Treatment: & $\mathrm{n}=12$ \\
Diuretics & \\
(Dose of frusemide or its & equivalent \\
ACE inhibitors & $(65 \cdot 0(11 \cdot 8) \mathrm{mg})$ \\
\hline
\end{tabular}

Values expressed as mean (SEM)

$\mathrm{FEV}_{1}$, forced expiratory volume in 1 second; FVC, forced vita capacity; NYHA, New York Heart Association classification of symptoms; MUGA, multigated acquisition radionuclide ven triculography; IHD, ischaemic heart disease; DCM, idiopathic dilated cardiomyopathy; ACE inhibitors, angiotensin-converting enzyme inhibitors.

${ }^{\star} 1 \mathrm{mg}$ bumetanide is taken as equivalent to $40 \mathrm{mg}$ frusemide.

The patients underwent treadmill cardiopulmonary exercise testing on two occasions breathing air or $100 \%$ oxygen in a randomised single blind manner using the Bruce protocol ${ }^{15}$ with the addition of a stage 0 at $1.0 \mathrm{mph}$ and $5 \%$ gradient. Each patient wore a noseclip and breathed through a pneumatic respiratory valve. The inspirate port was further connected to a $T$ valve placed away from the patient and, depending on the position of the $\mathrm{T}$ valve, the subject breathed either room air or $100 \%$ oxygen from a Douglas bag constantly refilled with oxygen. Respiratory gas exchange analysis (oxygen consumption, carbon dioxide output, minute ventilation) was carried out by means of breath-by-breath analysis using respiratory mass spectrometry and a heated pneumotachograph as above. ${ }^{16}$ The analysis of oxygen consumption during exercise on continuous inspired $100 \%$ oxygen was not possible because the software for analysis of peak oxygen consumption of our system was specific for inspired room air only. Heart rate, assessed electrocardiographically, and blood pressure, measured manually using a mercury sphygmomanometer, were recorded before exercise at the end of each three minute exercise stage and at peak exercise. Arterial oxygen saturation was measured with a pulse oximeter (Model N-200E, Nellcor, Hayward, California, USA). A forehead probe placed at

Table 3 Summary of the transient hyperoxic suppression of ventilation at rest and during mild exercise in controls and patients with chronic heart failure

\begin{tabular}{|c|c|c|c|}
\hline & $\begin{array}{l}\text { Controls } \\
(n=8)\end{array}$ & $\begin{array}{l}\text { Chronic heart } \\
\text { failure } \\
(n=13)\end{array}$ & Pvalue \\
\hline \multicolumn{4}{|l|}{ Rest: } \\
\hline Baseline minute ventilation $(1 / \mathrm{min})$ & $11.8(0.9)$ & $14 \cdot 5(1 \cdot 2)$ & $0 \cdot 13$ \\
\hline Post-hyperoxia minute ventilation $(1 / \mathrm{min})$ & $9 \cdot 8(1 \cdot 0)$ & $11 \cdot 8(1 \cdot 2)$ & $0 \cdot 19$ \\
\hline Magnitude of decrease in ventilation (\%) & $18 \cdot 1(2 \cdot 9)$ & $17 \cdot 9(2 \cdot 6)$ & NS \\
\hline \multicolumn{4}{|l|}{ Cycle ergometry $(25 \mathrm{~W})$ : } \\
\hline Minute ventilation $(1 / \mathrm{min})$ & $26 \cdot 0(1 \cdot 1)$ & $29 \cdot 7(1.5)$ & 0.056 \\
\hline Post-hyperoxia minute ventilation $(1 / \mathrm{min})$ & $20 \cdot 5(0 \cdot 2)$ & $23 \cdot 4(1 \cdot 1)$ & 0.025 \\
\hline Magnitude of decrease in ventilation (\%) & $20 \cdot 4(2 \cdot 8)$ & $21 \cdot 0(1 \cdot 6)$ & NS \\
\hline
\end{tabular}

Values expressed as mean (SEM). the right supraorbital artery region was used instead of an earlobe probe to provide maximal positional stability during treadmill exercise. At the end of each exercise stage and at peak exercise, the patient was also asked to score the level of dyspnoea and fatigue using a modified Borg scale. ${ }^{17}$ The scale rates the level of perceived symptoms from 0 (none) to 10 (maximum). Patients were also asked the major symptom which stopped them from continuing after each exercise testing.

The study was approved by the local ethics committee and subjects gave written informed consent.

\section{PULSE OXIMETRY VALIDATION}

The accuracy and reliability of the pulse oximeter used (Model N-200E, Nellcor, Hayward, California, USA) had been demonstrated in previous studies. ${ }^{18} 19$ In addition, we have also validated the accuracy of this pulse oximeter in 10 patients with cyanotic heart disease in our hospital and our findings (unpublished) accord with other studies. ${ }^{1819}$ Arterial blood samples obtained from these patients were analysed for oxygen saturation with a blood gas analyser (CIBA Corning) after two point calibration before each run. Mean oxygen saturation was $89.0(4.9) \%$ (range $79 \cdot 2$ to $94 \cdot 8 \%$ ). Simultaneous pulse oximetry measurements were performed. There was good agreement between the measurements obtained using the two methods $(r=0.97, \mathrm{P}<0.001)$. The mean difference between arterial oxygen saturation using pulse oximetry and that using direct arterial blood gas analysis, also known as bias, was $0.3 \%$ with an error of precision, defined as the standard deviation of the differences in arterial oxygen saturation using the two methods, of $1 \cdot 3 \%$. These values are compatible with previous studies. ${ }^{1819}$

\section{STATISTICAL ANALYSIS}

Statistical analysis was performed using paired and unpaired Student's $t$ tests as appropriate. $P<0.05$ was considered significant. Results are expressed as mean (SEM).

\section{Results}

PART 1

The results of the hyperoxic suppression of ventilation are summarised in table 3 . There was a trend towards a higher baseline ventilation at rest in patients with chronic heart failure $(P=0 \cdot 13)$. After the transient inhalation of $100 \%$ oxygen, there was a significant fall in ventilation of $2.0(0.4) \mathrm{l} / \mathrm{min}$ from baseline in healthy controls $(P=0.001)$ and $2.7(0.4)$ $1 /$ min in chronic heart failure $(P=0.0001)$ but the magnitude of fall was not significantly different between the two groups. The decrease in ventilation amounted to $18.1 \%$ of baseline ventilation in controls and $17.9 \%$ in patients with chronic heart failure ( $P=N S$ ). On average, the minute ventilation was smallest at the sixth breath for controls and seventh breath for chronic heart failure patients following inhalation of oxygen $(P=N S)$. During mild 
Table 4 Cardiopulmonary exercise results in 12 patients with chronic heart failure breathing air or continuous inspired $100 \%$ oxygen

\begin{tabular}{|c|c|c|c|}
\hline & Air & $100 \%$ Oxygen & $P$ value \\
\hline \multirow{8}{*}{ 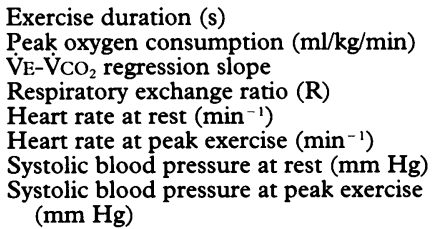 } & $455(27)$ & $517(31)$ & 0.003 \\
\hline & $18 \cdot 0(0 \cdot 6)$ & - & \\
\hline & $34 \cdot 19(2 \cdot 35)$ & $31 \cdot 27(2 \cdot 60)$ & 0.08 \\
\hline & $1 \cdot 26$ & & - \\
\hline & $73(3)$ & $72(3)$ & NS \\
\hline & $132(6)$ & $129(5)$ & NS \\
\hline & $118(7)$ & $121(7)$ & \\
\hline & $144(10)$ & $129(5)$ & NS \\
\hline
\end{tabular}

Values expressed as mean (SEM).

$\dot{\mathrm{V}}-\mathrm{VCO}_{2}$ regression slope is the slope of the regression line relating minute ventilation and carbon dioxide output during exercise and is a measure of the ventilatory response to exercise.

Table 5 Summary of the effects of continuous inspired $100 \%$ oxygen on minute ventilation, end tidal carbon dioxide, arterial oxygen saturation, and carbon dioxide production compared with air during incremental exercise testing

\begin{tabular}{|c|c|c|c|}
\hline & Air & $100 \%$ oxygen & Pvalue \\
\hline \multicolumn{4}{|l|}{ Rest: } \\
\hline Minute ventilation $(1 / \mathrm{min})$ & $13.9(1 \cdot 1)$ & $14 \cdot 3(2 \cdot 0)$ & NS \\
\hline End tidal $\mathrm{CO}_{2}(\%)$ & $4.95(0.17)$ & $4 \cdot 67(0 \cdot 26)$ & NS \\
\hline Arterial oxygen saturation (\%) & $100 \cdot 0(0)$ & $100 \cdot 0(0)$ & NS \\
\hline Carbon dioxide production $(\mathrm{ml} / \mathrm{min})$ & $332 \cdot 1(41 \cdot 5)$ & $300 \cdot 1(40 \cdot 5)$ & NS \\
\hline \multicolumn{4}{|l|}{3 minutes: } \\
\hline Minute ventilation $(1 / \mathrm{min})$ & $31.9(1.9)$ & $30 \cdot 2(2 \cdot 3)$ & NS \\
\hline End tidal $\mathrm{CO}_{2}(\%)$ & $5.05(0.15)$ & $5 \cdot 11(0 \cdot 22)$ & NS \\
\hline Arterial oxygen saturation (\%) & $99 \cdot 8(0 \cdot 1)$ & $100 \cdot 0(0)$ & $0 \cdot 17$ \\
\hline Carbon dioxide production $(\mathrm{ml} / \mathrm{min})$ & $838.9(68 \cdot 3)$ & $825 \cdot 2(69 \cdot 4)$ & NS \\
\hline \multicolumn{4}{|l|}{6 minutes: } \\
\hline Minute ventilation $(1 / \mathrm{min})$ & $48 \cdot 0(3 \cdot 7)$ & $43.8(2 \cdot 8)$ & $0 \cdot 10$ \\
\hline End tidal $\mathrm{CO}_{2}(\%)$ & $4.95(0.27)$ & $5 \cdot 18(0 \cdot 15)$ & NS \\
\hline Arterial oxygen saturation (\%) & $99 \cdot 5(0 \cdot 3)$ & $99 \cdot 9(0 \cdot 1)$ & 0.04 \\
\hline Carbon dioxide production $(\mathrm{ml} / \mathrm{min})$ & $1335 \cdot 7(87 \cdot 4)$ & $1229.9(61.5)$ & $0 \cdot 33$ \\
\hline \multicolumn{4}{|l|}{ Peak exercise: } \\
\hline Minute ventilation $(1 / \mathrm{min})$ & $57 \cdot 34(4 \cdot 7)$ & $58 \cdot 6(5 \cdot 8)$ & NS \\
\hline End tidal $\mathrm{CO}_{2}(\%)$ & $4.66(0.22)$ & $5.07(0.34)$ & $0 \cdot 19$ \\
\hline Arterial oxygen saturation (\%) & $99 \cdot 4(0 \cdot 3)$ & $99.9(0 \cdot 1)$ & 0.05 \\
\hline Carbon dioxide production $(\mathrm{ml} / \mathrm{min})$ & $1765 \cdot 0(110 \cdot 0)$ & $1896 \cdot 0(125 \cdot 0)$ & NS \\
\hline
\end{tabular}

Values expressed as mean (SEM). inspired $100 \%$ oxygen significantly increased exercise time. There was also a trend towards a reduction in the ventilatory response to exercise, as characterised by the shallower regression slope relating minute ventilation to carbon dioxide output, with inspired oxygen. A reduction in heart rate and systolic blood pressure at peak exercise was seen but this was not statistically significant. The effects of continuous inspired $100 \%$ oxygen on minute ventilation, end tidal carbon dioxide, arterial oxygen saturation, and carbon dioxide production are summarised in table 5 . There was a trend towards a reduction in minute ventilation at submaximal exercise. End tidal carbon dioxide concentration also increased steadily during exercise with inspired oxygen in contrast to the fall seen at peak exercise with air. In terms of arterial oxygen saturation, there was a small reduction in the peak value compared with that at rest when patients exercised breathing air. Continuous inspired oxygen minimised this drop in arterial oxygen saturation. The peak arterial oxygen saturation was also higher during oxygen breathing than air breathing. There was a non-statistically significant reduction in carbon dioxide production with inspired oxygen at rest and at submaximal exercise. The modified Borg scores for dyspnoea and for fatigue are given in table 6 . There was a trend towards an improvement in the symptom of dyspnoea at submaximal exercise with inspired oxygen compared with air $(-0.8$ at six minutes of exercise, $P=0.05)$. No significant difference was noted for fatigue. While they were breathing air the major limiting symptom at peak exercise was dyspnoea in 10 patients and fatigue in the remaining two patients. Of these 10 patients, the predominant limiting factor remained dyspnoea in eight of them whereas the other two became limited by fatigue while they were breathing oxygen. heart failure $(P<0.0001)$. Expressed as a percentage of the exercise minute ventilation before the inhalation of oxygen, this was $20.4 \%$ and $21.0 \%(P=N S)$ in healthy controls and chronic heart failure patients respectively. On average, the minute ventilation was smallest at the sixth breath for both groups of subjects after inhalation of oxygen during mild exercise.

Peripheral chemosensitivity at rest, as measured by the transient hypoxic ventilatory response test, was higher in patients $(0.572$ $(0.082)$ v $0.232(0.022) 1 / \mathrm{min} / \% \mathrm{SaO}_{2} ; \mathrm{P}=$ 0.002).

PART 2

The results of the treadmill cardiopulmonary exercise test are shown in table 4. Continuous

\section{Discussion}

PART 1

The contribution of peripheral chemoreceptors to ventilation in patients with chronic heart failure is hitherto unknown. We have shown in this study that when the peripheral chemoreceptor drive was suppressed by transient hyperoxia, the percentage reduction in ventilation in patients with chronic heart failure was not significantly different from that in healthy controls despite the fact that these patients have an increased peripheral chemoreceptor sensitivity. There are two possible explanations. The first is that peripheral chemoreceptors are not an important factor in

Table 6 Modified Borg scores for dyspnoea and for fatigue with air and contion
there may be reduction in the perception of dyspnoea at submaximal exercise

\begin{tabular}{|c|c|c|c|c|c|c|}
\hline & \multicolumn{3}{|c|}{ Borg score (dyspnoea) } & \multicolumn{3}{|c|}{ Borg score (fatigue) } \\
\hline & Air & $100 \%$ oxygen & Pvalue & Air & $100 \%$ oxygen & Pvalue \\
\hline $\begin{array}{l}3 \text { minutes } \\
6 \text { minutes } \\
\text { Peak exercise }\end{array}$ & $\begin{array}{l}1.17(0.35) \\
3.60(0.22) \\
5.67(0.74)\end{array}$ & $\begin{array}{l}1.33(0.28) \\
2.75(0.37) \\
5.75(0.48)\end{array}$ & $\begin{array}{l}\text { NS } \\
0 \cdot 05 \\
\text { NS }\end{array}$ & $\begin{array}{l}1.33(0.36) \\
3.00(0.49) \\
5.71(0.54)\end{array}$ & $\begin{array}{l}1.25(0.30) \\
2.79(0.39) \\
5.92(0.63)\end{array}$ & $\begin{array}{l}\text { NS } \\
\text { NS } \\
\text { NS }\end{array}$ \\
\hline
\end{tabular}

Values expressed as mean (SEM) 
the mediation of the ventilatory response to exercise and however increased the chemosensitivity may be, it has little influence on exercise ventilation. This is probably unlikely because peripheral chemosensitivity correlates well with ventilatory response to exercise both in healthy individuals ${ }^{20}$ and also in patients with chronic heart failure. ${ }^{4}$ Furthermore, in subjects with bilateral carotid body resection for the management of asthma, the exercise ventilatory dynamics are known to be significantly delayed. ${ }^{21}$ The second and more plausible explanation is that the input from other modulators of exercise ventilation in chronic heart failure is also increased so that despite an augmented peripheral chemosensitivity, the overall contribution of the peripheral chemoreceptors to ventilation remains similar to that in controls. Other than the peripheral chemoreflex, modulators such as central chemoreflex, ${ }^{4}$ ergoreflex ${ }^{10}$ and cardiac mechanoreflex ${ }^{7-9}$ may also play a part-all interacting to produce the exercise hyperpnoea seen in these patients. The tendency to hyperpnoea was demonstrated even at rest and during mild exercise in patients with chronic heart failure in this study in keeping with previous data. ${ }^{1}$

The increased peripheral chemoreceptor sensitivity in these patients may be the result of several factors. There is sympathetic overactivity in chronic heart failure and this is known to potentiate peripheral chemosensitivity. ${ }^{22}$ In addition, arterial baroreflex is known to inhibit chemoreflex activity ${ }^{23}$ and thus the impaired baroreflex sensitivity in patients with chronic heart failure may also augment chemosensitivity. Another possible factor causing an increased peripheral chemosensitivity is ischaemic hypoxia due to a reduction in carotid chemoreceptor blood flow $^{24}$ since peripheral blood flow is known to be reduced in chronic heart failure patients. ${ }^{25}$

PART 2

The second part of this study was to investigate the effects of continuous inspired oxygen on exercise tolerance in patients with chronic heart failure. We have shown that inspired oxygen increased exercise duration. This is compatible with previous studies of healthy controls $^{26-29}$ and patients with chronic heart failure. ${ }^{30}$ There are several possible ways that oxygen may improve exercise tolerance in these patients. Firstly, we have earlier shown that oxygen suppresses the peripheral chemoreceptor drive and consequently reduces ventilation. With reduced ventilation, the work of breathing is conceivably also reduced and this may have contributed to the increased exercise tolerance. There was also a small but non-significant reduction in heart rate and blood pressure with continuous inspired oxygen. This is consistent with the reduction in sympathetic drive secondary to peripheral chemoreflex suppression. ${ }^{31}$ The reduction in sympathetic drive may also have helped to improve exercise tolerance by reducing cardiac work. Secondly, we also noted a concomitant reduction in the perception of breathlessness: this also accords with other studies. ${ }^{2629} 30$ Thus symptom reduction may also have contributed to the increased exercise tolerance. This study, however, does not provide any information regarding the nature of the relation between dyspnoea and ventilation despite their close association. It may be that the afferent signals from the peripheral chemoreceptors not only act on the medullary respiratory centres but are also directly perceived as breathlessness. On the other hand, the effects of oxygen on ventilation and breathlessness may be two separate entities with oxygen having a direct effect on the sensory cortex modifying the perception of dyspnoea. ${ }^{29}$

The third possible mechanism by which oxygen may improve exercise tolerance is by increasing oxygen delivery to the muscles and hence reducing anaerobic metabolism. ${ }^{28}$ Although we did not measure plasma lactate, there was only a non-significant reduction in carbon dioxide production during submaximal exercise with oxygen breathing which may reflect only a slight facilitation of aerobic metabolism of exercising muscles. Moreover, in one previous study in patients with chronic heart failure oxygen delivery remained unchanged despite increased arterial oxygen saturation with oxygen breathing because of the associated reduction in cardiac output. ${ }^{30}$ In another study, reducing intramuscular lactic acidosis with dichloroacetate did not improve exercise tolerance in heart failure patients. ${ }^{32}$ Thus, bearing these considerations in mind, it may well be that the mechanism of increased exercise tolerance with oxygen breathing in chronic heart failure is to a large extent secondary to its suppressive effects on the peripheral chemoreceptors with the associated reduction in ventilation, breathlessness, and sympathetic drive as discussed above. It is also pertinent to note that the two patients who were limited by muscle fatigue when they exercised while breathing air remained limited by fatigue despite inspired oxygen. On the contrary, of the 10 patients who were limited by dyspnoea when exercising breathing air, eight were limited by dyspnoea while inspiring oxygen. Thus it appears that inspired oxygen may modify the perception of breathlessness more than it does fatigue. None of the patients with ischaemic heart disease had angina or demonstrated electrocardiographic ischaemic changes during exercise testing. It is therefore unlikely that the reduction of myocardial ischaemia with inspired oxygen played an important role in improving exercise tolerance in this subgroup of patients.

With continuous inspired oxygen, there was only a trend for ventilation during exercise to be reduced whereas there was significant hypoventilation with transient hyperoxia. This may be because with continuous inspired oxygen, exercise involved higher workrates (hence more ventilatory drive) whereas with transient hyperoxia, mild exercise was used. More importantly, as alluded to earlier, with continuous inspired oxygen, changes in secondary factors affecting ventilation, such as increased arterial carbon dioxide tension and a lowered 
arterial $\mathrm{pH}$ consequent to hyperoxia-induced hypoventilation and to the Haldane effect, ${ }^{33}$ may increase ventilation by acting on central chemoreceptors. Also with hyperoxia, there may be a decrease in cerebral blood flow causing cerebral acidosis with the consequence of stimulating ventilation. ${ }^{12}$ All these opposing factors may therefore have resulted in less of a reduction in ventilation with continuous inspired oxygen than with transient hyperoxia.

\section{CONCLUSION}

Despite an increased peripheral chemoreceptor sensitivity, the proportionate contribution of peripheral chemoreceptors to ventilation in chronic heart failure appeared similar to healthy controls. This suggests that peripheral chemoreceptors are not the main mediator of increased ventilation in these patients and that there are other factors involved. Transient hyperoxia reduced ventilation in patients with chronic heart failure by suppressing the peripheral chemoreceptor drive. The finding that exercise duration increased with continuous inspired oxygen associated with a reduction in the exercise ventilatory response suggests that peripheral chemoreceptor suppression may also improve exercise tolerance although our study does not exclude the possible effects of a reduced skeletal muscle anaerobiosis.

\section{LIMITATIONS OF THE STUDY}

There are limitations to this study. We assumed that peripheral chemoreceptor drive was abolished with inhalation of three breaths of pure oxygen, as it was by a single or two breaths of oxygen in normal subjects. ${ }^{5}$ It is possible that because of the increased peripheral chemosensitivity in patients with chronic heart failure, the three breaths of oxygen did not abolish the chemoreceptor drive and hence the percentage reduction in ventilation was less than expected. We did not attempt to prolong oxygen inhalation because this as well as suppressing the peripheral chemoreceptor drive also can provoke changes in other secondary factors that increase ventilation, such as increased arterial carbon dioxide tension, a lowered arterial $\mathrm{pH}$, and a decrease in cerebral blood flow.

Arterial oxygen saturation was measured transcutaneously with a pulse oximeter. Although not as accurate as direct arterial blood gas analysis, the particular model of pulse oximeter (Model N-200E, Nellcor, Hayward, California, USA) used in this study is accurate and reliable. ${ }^{1819}$ However, oxygen saturations of $>95 \%$, are occasionally registered as $100 \%$ on pulse oximeters. ${ }^{34}$ This may have led to errors in the absolute arterial oxygen saturation readings in the second part of the study which investigated the effects of continuous inspired oxygen on exercise tolerance. Nevertheless, it is very unlikely to affect the general findings of this study.

We did not measure plasma lactate during exercise in our study. This would have provided more information. However, a previous study showed that lactic acidosis did not influ- ence exercise tolerance in patients with chronic heart failure. ${ }^{31}$ In another study in healthy subjects, it was shown that the change in plasma lactate concentrations was too slow to explain the change in ventilation with inspired oxygen. ${ }^{28}$ Thus the direct effects of oxygen on the peripheral chemoreceptors are probably more important.

TPC is a British Heart Foundation Junior Research Fellow. PPP is supported by the European Society of Cardiology and DH by the Robert Luff Foundation, UK. AJSC is the Viscoun Royston and British Heart Foundation Senior Lecturer in Cardiomyopathy.

1 Sullivan MJ, Higginbotham MB, Cobb FR. Increased exercise ventilation in patients with chronic heart failure: intact ventilatory control despite hemodynamic and pulmonary abnormalities. Circulation 1988;77:552-9.

2 Buller NP, Poole-Wilson PA. Mechanism of the increased ventilatory response to exercise in patients with chronic heart failure. Br Heart $\mathcal{1}$ 1990;63:281-3.

3 Rubin SA, Brown HV. Ventilation and gas exchange during exercise in severe chronic heart failure. Am Rev Respir Dis 1984;129(suppl): S63-S64.

4 Chua TP, Clark AL, Amadi AA, Coats AJS. Relation between chemosensitivity and the ventilatory response to exercise in chronic heart failure. $₹ \mathrm{Am}$ Coll Cardiol 1996; 27:650-7.

5 Dejours P. Chemoreflexes in breathing. Physiol Reviews 1962;42:335-58.

6 Eldridge FL, Millhorn DE, Kiley JP, Waldrop TG. Stimulation by central command of locomotion, respiration and circulation during exercise. Resp Physiol 1985 59:313-37.

7 Jones PW, Huszczuk A, Wasserman K. Cardiac output as a controller of ventilation through changes in right ventricular load. $\mathcal{f}$ Appl Physiol 1982;53:218-24.

8 Uchida Y. Afferent sympathetic nerve fibers with mechanoreceptors in the right heart. Am $\mathcal{F}$ Physiol 1975;228: 223-30.

9 Uchida $Y$. Tachypnea after stimulation of afferent cardiac sympathetic nerve fibers. Am F Physiol 1976;230:1003-7.

10 Iaria CT, Jalar UH, Kao FF. The peripheral neural mechanism of exercise hyperpnoea. $\mathcal{F}$ Physiol (London) 1959;29: 49P-50P.

11 Wassermann $\mathrm{K}$. Testing regulation of ventilation with exercise. Chest 1976;70:S173-S178.

12 Jeyaranjan R, Goode R, Beamish S, Duffin J. The contribution of peripheral chemoreceptors to ventilation during tion of peripheral chemoreceptors to ventilation
heavy exercise. Resp Physiol 1989;68:203-13.

13 Sietsema KE, Ben-Dov I, Zhang YY, Sullivan C, Wasserman K. Dynamics of oxygen uptake for submaximal exercise and recovery in patients with chronic hear failure. Chest 1994;105:1693-700.

14 Chua TP, Coats AJS. The reproducibility and comparability of tests of the peripheral chemoreflex: comparing the transient hypoxic ventilatory drive test and the singlebreath carbon dioxide response test in healthy subjects. Eur $\mathcal{Y}$ Clin Invest 1995;25:887-92.

15 Bruce RA, Blackman JR, Jones JW. Exercise testing in adult normal subjects and cardiac patients. Pediatrics 1963;32:742-55.

16 Beaver WL, Wasserman K, Whipp BJ. On-line computer analysis and breath-by-breath graphical display of exeranalysis and breath-by-breath graphical display of

17 El-Manshawi A, Killian KJ, Summers E, Jones NL Breathlessness during exercise with and without resistive Breathlessness during exercise with and
loading. $₹$ Appl Physiol 1986;61:896-905.

18 Hannhart B, Michalski H, Delorme N, Chapparo G, Polu J. Reliability of six pulse oximeters in chronic obstructive pulmonary disease. Chest 1991;99:842-46.

19 Barker SJ, Hyatt J, Shah NK, Kao J. The effect of sensor malpositioning on pulse oximeter accuracy during hypoxemia. Anesthesiology 1993;79:248-54

20 Martin BJ, Weil JV, Sparks KE, McCullough RE, Grover RF. Exercise ventilation correlates positively with ventilatory chemoresponsiveness. I Appl Physiol 1978;45: 557-64.

21 Wasserman K, Whipp BJ, Koyal SN, Cleary MG. Effect of carotid body resection on ventilatory and acid-base control during exercise. $₹ \mathrm{Appl}$ Physiol 1975;39:354-8.

22 Cunningham DJC, Hey EN, Patrick JM, Lloyd BB. The effect of noradrenaline infusion on the relation between effect of noradrenaline infusion on the relation between
pulmonary ventilation and the alveolar $\mathrm{PO}_{2}$ and $\mathrm{PCO}_{2}$ in pulmonary ventilation and the alveolar $\mathrm{PO}_{2}$
man. Ann N Y Acad Sci 1963;109:756-71.

23 Shepherd JT. Circulatory response to exercise in health. Circulation 1987;76(suppl VI):VI-3-VI-10.

24 Fidone SJ, Gonzalez C. Initiation and control of chemoreceptor activity in the carotid body. In: Cherniack NS, ceptor activity in the carotid body. In: Cherniack NS, Widdicombe JG, eds. Handbook of physiology, Section 3: The respiratory system, Vol 2-Control of breathing.
Bethesda: American Physiological Society, 1986: Bethesda:

25 Levine TB, Levine AB. Regional blood flow supply and demand in heart failure. Am Hear $₹$ 1990;120:1547-51.

26 Bannister RG, Cunningham DJC. The effects on the respiration and performance during exercise of adding oxygen to the inspired air. $\mathcal{P}$ Physiol (London) 1954;125:118-37.

27 Asmussen E, Nielsen M. Pulmonary ventilation and effect 
of oxygen breathing in heavy exercise. Acta Physiol Scand 1958;43:365-78.

28 Kozlowski S, Rasmussen B, Wilkoff WG. The effect of high oxygen tensions on ventilation during severe exercise. oxygen tensions on ventilation during
Acta Physiol Scand 1971;81:385-95.

29 Chronos N, Adams L, Guz A. Effect of hyperoxia and hypoxia on exercise-induced breathlessness in normal

subjects. Clin Sci 1988;74:531-7.
30 Moore DP, Weston AR, Hughes JMB, Oakley CM, Cleland JGF. Effects of increased oxygen concentrations on exercise performance in chronic heart failure. Lancet 1992;339:950-3.
31 Floras JS. Clinical aspects of sympathetic activation and parasympathetic withdrawal in heart failure. $\mathcal{F} \mathrm{Am}$ Coll Cardiol 1993;22 (suppl A):72A-84A

32 Wilson JR, Mancini DM, Ferraro N, Egler J. Effect of dichloroacetate on the exercise performance of patients dichloroacetate on the exercise performance of patie
with heart failure. $7 \mathrm{Am}$ Coll Cardiol 1988;12:1464-9.

33 Guyton AC. Transport of oxygen and carbon dioxide in the blood and body fluids. In: Textbook of medical physiology. 8th ed. Philadelphia: WB Saunders, 1991:433-53.

34 Webb RK, Ralston AC, Runciman WB. Potential errors in pulse oximetry. Effects of changes in saturation and signal quality. Anaesthesia 1991;46:207-12.

\section{IMAGES IN CARDIOLOGY}

\section{Echocardiographic diagnosis of a subvalvar aortic membrane}

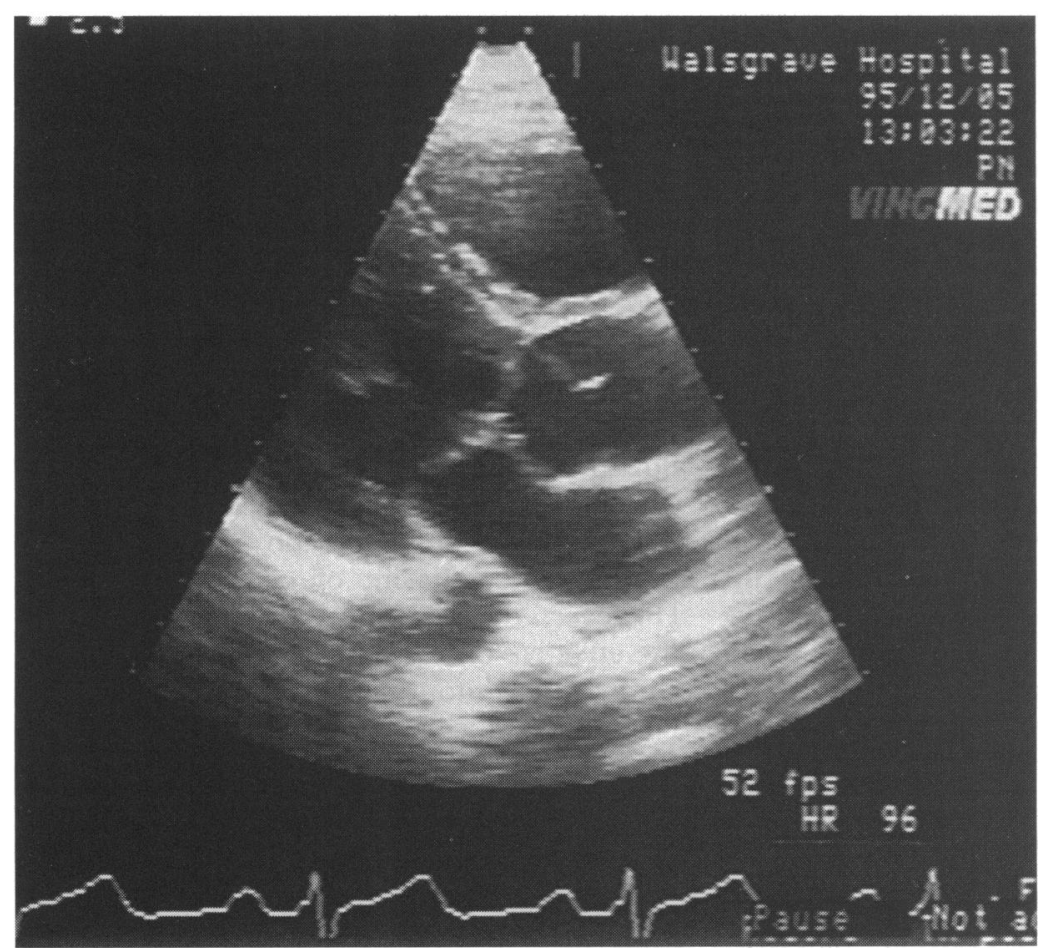

A 14 year old boy with an aortic systolic murmur complained of progressive shortness of breath on exertion over one year. Transthoracic echocardiography four years earlier had shown an aortic outflow gradient of $26 \mathrm{~mm} \mathrm{Hg}$. A repeat echocardiogram showed left ventricular hypertrophy and a gradient of $90 \mathrm{~mm} \mathrm{Hg}$ across the aortic valve. $\mathrm{He}$ underwent cardiac catheterisation and was found to have a gradient of $60 \mathrm{~mm} \mathrm{Hg}$ below the level of the aortic valve with no gradient at valve level. A repeat echocardiogram identified a subvalvar aortic membrane. $\mathrm{He}$ is now awaiting surgery to resect the membrane.

K K RAY M HALIM H SINGH 